\title{
A Novel Anti-Parkinsonian Agent, Zonisamide, Attenuates MPTP-Induced Neurotoxicity in Mice
}

\author{
Ryohei Yano $\cdot$ Hironori Yokoyama $\cdot$ Hayato Kuroiwa • \\ Hiroyuki Kato $\cdot$ Tsutomu Araki
}

Received: 11 November 2008 / Accepted: 19 January 2009/Published online: 27 May 2009

(C) Humana Press 2009

\section{Erratum to: J Mol Neurosci \\ DOI 10.1007/s12031-009-9181-z}

In the original publication, the caption to Figure 6 contains a mistake in the description of parts $\mathrm{C}$ and $\mathrm{D}$. The full caption in its correct form is as follows.

Figure 6 Immunoblotting analysis of $\mathrm{TH}(\mathbf{A}, \mathbf{B})$ and GFAP $(\mathbf{C}, \mathbf{D})$ protein levels in the mouse striatum 1 day after zonisamide treatment. A, C Western blot analysis; GAPDH protein was detected as a house keeping protein to confirm that equal amounts of protein were loaded in each line. B TH protein levels were expressed as \% of vehicle (mean \pm SEM) using ratios to GAPDH protein levels. D GFAP protein levels were expressed as $\%$ of vehicle (mean \pm SEM) using ratios to GAPDH protein levels. ${ }^{*} P<0.05$ compared with vehicle group (Mann-Whitney $U$ test). Vehicle $1 \%$ Tween 80 ; ZNS(20) zonisamide $20 \mathrm{mg} / \mathrm{kg}$, i.p.; $n=3-4$ mice.

The online version of the original article can be found found at http://dx. doi.org/10.1007/s12031-009-9181-z.

R. Yano $\cdot$ H. Yokoyama $\cdot$ H. Kuroiwa $\cdot$ T. Araki $(\bowtie)$

Department of Neurobiology and Therapeutics,

Graduate School and Faculty of Pharmaceutical Sciences,

The University of Tokushima,

Tokushima 770-8505, Japan

e-mail: tsuaraki@ph.tokushima-u.ac.jp

H. Kato

Department of Neurology, Organized Center of Clinical Medicine, International University of Health and Welfare,

Tochigi, Japan 